\title{
The Supreme Court Weighs in on Local Exchange Competition: The Meta-Message
}

\author{
DAVID L. KASERMAN
}

Auburn University

and

JOHN W. MAYO*

Georgetown University

\begin{abstract}
The Supreme Court Opinion on local exchange competition in general and on pricing and unbundling in particular was much anticipated and will be much discussed. Because of the very technical nature of the pricing and unbundling rules facing incumbent local exchange carriers there is a considerable risk that students of the Court's Opinion will be mired in the details of that Opinion and miss what we believe is a clear, unequivocal meta-message embedded in the Opinion. Specifically, this decision unequivocally affirms a fundamental shift in regulatory policy reflected in the Telecommunications Act of 1996. That is, the Act dictates that regulators act not merely to disable monopoly but to adopt policies that affirmatively enable competition. The Court's Opinion now confirms this interpretation of the congressional intent behind the legislation. Thus, while it is fair to say that the Court's specific decision with respect to the pricing and unbundling issues represents an important component of a regulatory policy designed to promote competition in local exchange telephony, there is a larger lesson embedded in the Court's reading of the Telecommunications Act. In this paper we first consider in some detail the Opinion and how it reflects an unambiguous endorsement of a competition-enabling framework for the development of local exchange competition. Next, we point out that, despite the Court's unambiguous and clear ruling, a dispassionate scrutiny of economic and regulatory conditions present in local exchange markets - even in the wake of the Court's ruling - reveals a number of extraordinary obstacles to the successful emergence of effective local exchange competition that still remain.
\end{abstract}

\section{Introduction}

As witnessed by this volume, the recent Supreme Court decision affirming the legality of the Federal Communications Commission's (FCC's) policies regarding the pricing and unbundling of incumbent local exchange company (ILEC) network elements will certainly draw immediate and critical attention. Much of this attention will likely be focused on the

* Contact author. Mailing Address: McDonough School of Business, Georgetown University, Washington, D.C., U.S.A. 20057. E-Mail address: Mayoj@Georgetown.edu. We appreciate the helpful comments of Rich Clark, Robert Mulvee, and Carol Wilner on a prior draft of this paper. Naturally, we alone are responsible for any errors that remain. 
technical merits of the Court's decision, specifically with respect to the FCC's pricing and unbundling requirements. While such scrutiny is entirely appropriate, it raises the prospect that the larger message reflected in this decision will be missed.

In particular, we believe that there is an important message to be drawn from the Court's Opinion that goes well beyond the specific issues of TELRIC pricing and unbundling requirements. Specifically, this decision unequivocally affirms the fundamental shift in regulatory policy reflected in the Telecommunications Act of 1996. As we have argued elsewhere, that Act mandates a fundamental regime shift for federal and state regulators. ${ }^{1}$ Namely, the Act imposes a new obligation not only to allow competition to emerge in formerly protected markets but also to adopt policies designed to facilitate such emergence. That is, the Act dictates that regulators act not merely to disable monopoly but to adopt policies that affirmatively enable competition. ${ }^{2}$ The Court's Opinion now confirms this interpretation of the congressional intent behind the legislation.

Thus, while it is fair to say that the Court's specific decision with respect to the pricing and unbundling issues represents an important component of a regulatory policy designed to promote competition in local exchange telephony, there is a larger lesson embedded in the Court's reading of the Telecommunications Act. This lesson is developed in Section 2 below. Section 3, then, considers the implications of this new mandate for federal and state-level regulators that go beyond the more narrow issues dealt with in the Opinion. Specifically, we point out that, despite the Court's unambiguous and clear ruling, a dispassionate scrutiny of economic and regulatory conditions present in local exchange markets - even in the wake of the Court's ruling - suggests a number of extraordinary obstacles to the successful emergence of effective local exchange competition that still remain. Section 4 then concludes.

\section{Competition-enabling policies: A fundamental shift in regulatory mandate}

The Telecommunications Act of 1996 represents a path-breaking piece of legislation in a variety of ways. At the most basic level, however, the truly novel aspect of the Act was its subtle but, we believe, unequivocal call for a change in the regulatory mandate in the telecommunications industry. Specifically, unlike prior public policies towards the telecommunications industry, which had sought first to control monopoly and later to disable monopoly, the passage of the Telecommunications Act signaled a new mandate that regulators at both the federal and state levels should implement policies specifically designed to enable competition. As we shall see in this section, this last set of policies is fundamentally different from prior policies that had been applied to the telecommunications industry.

The traditional economic rationale for regulation of the telecommunication industry is that the services supplied over the public switched telephone network have been subject to

\footnotetext{
1 See Kaserman and Mayo (1999).

2 It is important at the outset to emphasize the distinction between policies designed to facilitate entry and thereby enable competition and policies designed to promote "infant firms" through subsidizing actions. While the former is, we believe, the best vehicle to promote the long-run viability of effective competition, economists have properly subjected the later approach to considerable criticism.
} 
natural monopoly supply. ${ }^{3}$ Beginning with Hush-a-Phone and continuing through the divestiture agreement in 1982 which separated AT\&T from the Bell operating companies, it was increasingly recognized that not all telecommunications services were necessarily subject to natural monopoly conditions. As the Court aptly notes in its most recent decision, however, "The [1982 divestiture] decree did nothing ...to increase competition in the persistently monopolistic local markets, which were thought to be the root of natural monopoly in the telecommunications industry". ${ }^{4}$

Indeed, simplifying only slightly, it is fair to say that prior to the passage of the Telecommunications Act of 1996, two principal methods were utilized to deal with the monopoly problems created by the structure of the telecommunications industry. First, a surgical approach involving structural separation of the monopoly from competitive elements within the industry was used to prevent remaining monopoly elements from impeding the growth of competition in potentially non-monopoly segments. This approach was the central feature of the 1982 Modification of Final Judgment that led to the divestiture of AT\&T from the Bell Operating Companies. The second, less draconian, approach has been to leave in place the combination of monopoly and potentially competitive elements of the industry, but to seek to protect competitors - both potential and actual - from monopolistic practices of the incumbent through regulatory rules, or safeguards. Certainly with respect to the services provided by the Regional Bell Operating Companies (RBOCs), the pre-1996 Act policies of the FCC and state regulatory commissions were largely consistent with this latter approach.

As we have argued elsewhere, however, both of these regulatory approaches toward the telecommunications industry suffer drawbacks. ${ }^{5}$ Specifically, while the structural separations approach can eliminate both the incentive and ability to engage in monopoly leveraging from non-competitive to competitive markets, it has the prospect of eliminating any economies of scope that may exist in the joint production of monopoly and potentially competitive services. Alternatively, the regulatory rules approach preserves the potential realization of economies of scope by permitting the firm to remain intact, but necessarily involves costly and potentially complex rules that seek to prevent the incumbent from using its monopoly power to impede the emergence of competition. Moreover, such regulatory rules often fail to achieve the intended effects, as incumbents are able to devise novel approaches that circumvent these constraints. ${ }^{6}$

A third approach, which we have advocated and which the Supreme Court has now found to be the bedrock of the Telecommunications Act of 1996 is for regulators to fundamentally shift their approach toward incumbent local exchange providers. Specifically, this approach calls upon regulators to shift their agendas from controlling or disabling monopolies to a more active policy of enabling competition. Such a shift requires that regulators affirmatively engage in a variety of non-traditional policies that are designed to facilitate the emergence of competition. Among these, competition enabling requires that regulators aggressively act to: (1) eliminate barriers to entry; (2) classify monopoly and "effectively competitive" services (moving expeditiously to deregulate the later); (3) adopt

\footnotetext{
3 As Justice Breyer notes in his dissenting opinion, "For decades experts justified regulation on the ground that telecommunications providers were 'natural monopolists,' i.e., telecommunications markets would not support more than one firm of efficient size." (p. 7)

4 Opinion, p. 2.

5 For a more detailed discussion, see Kaserman and Mayo (1999).

${ }^{6}$ See Stelzer (1997) and Beard, Kaserman and Mayo (2002).
} 
efficient pricing policies, particularly for inputs required by competitors; and, (4) eliminate all internal cross-subsidies for retail regulated services. In recognition of the necessarily "mixed" monopoly and competitive environment that will inevitably exist in the short run, competition enabling also requires that regulators unbundle network elements, require unrestricted resale and ensure, insofar as possible, nondiscriminatory interconnection policies.

Importantly, the Court's Opinion explicitly recognizes that the Telecommunications Act does indeed call for a fundamental regulatory regime shift that is consistent with a competition-enabling (C-E) policy agenda. For example, at page 15, the Opinion points out that Congress sought to reject the traditional regulatory approach that had prevailed prior to the Act.

[O]ne possible lesson was drawn by Congress in the 1996 Act, which was that regulation using traditional rate-base methodologies gave monopolies too great an advantage and that the answer lay in moving away from the assumption common to all rate-base methods, that the monopolistic structure within the discrete markets would endure. ${ }^{7}$ (emphasis added)

The call for a regulatory regime shift is further emphasized by the Court when it observes:

Congress called for ratemaking different from any historical practice, to achieve the entirely new objective of uprooting the monopolies that traditional rate-base methods had perpetuated. ${ }^{8}$ (emphasis added)

The desire by Congress to implement a C-E policy approach is underscored again by the Court when it states that:

For the first time, Congress passed a ratesetting statute with the aim not just to balance the interests between sellers and buyers, but to reorganize markets by rendering regulated utilities' monopolies vulnerable to interlopers..." (emphasis added)

and

Thus, the Act appears to be an explicit disavowal of the familiar public-utility model...in favor of novel ratesetting designed to give aspiring competitors every possible incentive to enter local retail telephone markets, short of confiscating the incumbents' property. ${ }^{10}$ (emphasis added)

The importance of the intent of Congress to foster C-E policies cannot be overstated in an environment that has been, and certainly will continue to be, rife with uncertainty and contradictory interpretations of ambiguities that exist in either the law or economics regarding the implementation of the Act. For example, in its determination of the legality of the TELRIC standard for pricing, the Court is immediately drawn into the sticky issue of what is meant by the term "cost" in the 1996 Act. ${ }^{11}$ The Court recognizes that in the absence of additional defining language, the term cost is a "virtually meaningless term" and "a chameleon". 12 In light of this ambiguity, the Court finds - on legal grounds - that it cannot overturn the FCC's interpretation of the term "cost". Somewhat more subtly, but equally importantly for the future, is the Court's implicit recognition that the FCC's adoption of the TELRIC pricing principle is consistent with Congressional intent that calls

\footnotetext{
Opinion, p. 15

Opinion, pp. 15-16.

Opinion, p. 16.

Opinion, p. 17.

11 Opinion, p. $26 \mathrm{ff}$.

12 Opinion, pp. 28-29.
} 
upon regulators to implement C-E policies. In so doing, the Court requires that regulators' policies be in harmony with Congress' intent to enable competition.

Another critical component of the Court's Opinion is its recognition that ILECs continue to enjoy substantial incumbency advantages and that passive policies or halfhearted attempts to "open" local exchange markets to competition are likely to fail. For instance, the Court notes that:

Thus, it is easy to see why a company that owns a local exchange...would have an almost insurmountable competitive advantage not only in routing calls within the exchange, but, thorough its control of this local market, in the markets for terminal equipment and long-distance as well. ${ }^{13}$

In sum, the Court's Opinion is likely to draw considerable attention regarding its support for the FCC's specific TELRIC pricing and unbundling requirements. Perhaps more important, however, is the endorsement by the Court of the need for regulators, acting under the Telecommunications Act, to aggressively pursue $\mathrm{C}$-E polices and its recognition that unless such policies are pursued vigorously and steadfastly, the powers of incumbency and monopoly are likely to prevail. Indeed, as we shall argue in the next section, while the Court has given clear support for the unbundling and pricing rules of the FCC, a number of other "trouble spots" lie in the wings that, despite this ruling, stand to impede the growth of competition in local exchange telephony.

\section{Impediments to competition}

Significant hopes were raised that competition could be fostered in local exchange markets by the 1996 Act. Those hopes have been at least partially reignited by the Supreme Court's recent affirmation of the legal authority of the FCC to adopt and impose UNE pricing and unbundling/rebundling rules that are relatively favorable to entrants. Nonetheless, a number of "dark clouds" remain on the horizon that represent substantive obstacles that must still be overcome before effective competition can emerge in local exchange retail markets. Specifically, at least four types of impediments to local exchange competition remain looming on the horizon, the Supreme Court's Opinion notwithstanding.

\subsection{Other, non-UNE distortions}

The Supreme Court Opinion unequivocally provides authority to the FCC to implement TELRIC pricing for unbundled network elements. The breadth of inputs that constitute such "elements" and are, therefore, subject to TELRIC principles, however, is not addressed by the Court's decision. This issue of UNE definition potentially presents a set of critical obstacles still facing the CLECs. These obstacles fall into two categories: pricing and availability. In the realm of pricing, federal and state regulators must set prices for certain network "elements" or inputs that may not fall under the scope of the narrowly interpreted letter of the Telecommunications Act. The most obvious example, of course, is the pricing of access to the local exchange network when the transmission involves a longdistance call.

Although it may not be an "element" under the Act, such access is clearly a necessary input for any telephone company that wishes to compete either in the long-distance arena or, as is more and more likely, across both local and long-distance calling. Indeed, the

13 Opinion, p. 18. 
access required by a long-distance carrier to complete a call to a given customer is virtually identical to the local call termination service required by a CLEC to complete a call to the same customer. While the former service (access) is not considered to be a network element under the Act, the later service (local call termination) is. But as has often been stated in regulatory arenas "a minute is a minute is a minute." Historically, however, the prices for such access services have been held well above economically efficient prices. Indeed, despite the fact that economists have recognized the inefficiencies embedded in access charges for years and these charges have generally fallen, access continues to remain well above its economic costs. ${ }^{14}$

For example, in a recent study of state-level access charges, we found that they vary from rough parity with UNE rates for terminating access (e.g., in Illinois) to over 25 times the respective UNE rate for such access (e.g., in Virginia). ${ }^{15}$ The economic case to reconcile the level of access charges with the underlying TELRIC rates (which we make elsewhere) is compelling and should provide an impetus for regulators to further reform these access charges. ${ }^{16}$ The Court's "green light" to the enactment of C-E policies hopefully will provide additional stimulus to state and federal regulatory commissions to implement such reform. This process, however, will necessarily involve numerous statelevel regulatory proceedings that, unless expedited, may amount to providing mouth-tomouth resuscitation to the already drowned victim. ${ }^{17}$

Another critical issue related to the pricing of "non-UNEs" centers on the one-time fees, known as non-recurring charges or NRCs that are assessed on the new entrants whenever a customer chooses to switch from the incumbent to the new entrant. Ostensibly, the same guiding principles that drive the pricing of recurring purchases of elements would drive the pricing of NRCs. This, however, has not necessarily been the case. For instance, costs are incurred in making a "hot cut" transition of a loop from an ILEC to a CLEC. The amount of the costs that should be recovered by the ILEC is, however, subject to considerable debate. In a recent case in New York, the prevailing NRC for a hot cut was about \$24. The incumbent, however, claimed that the forward-looking costs for providing this hot cut service were roughly $\$ 225$ and that any CLEC seeking such a hot cut should be made to pay this charge. Although the New York Public Service Commission initially ordered a rate of about $\$ 135$, the ultimate rate approved by the regulatory commission (\$35) as part of an overall settlement concerning the ILEC's regulatory plan was considerably less than the ILEC's claimed costs. Nevertheless, this example provides powerful testimony that the ability of incumbents to delay or forestall competition does not end with the recurring UNEs. ${ }^{18}$

Yet another critical pricing issue that is likely to continue to haunt the new entrants (and thus the competition that is sought under the Telecommunications Act) is the

\footnotetext{
${ }^{14}$ For early discussions of the inefficiencies embedded in telephone pricing, see Kahn (1984) and Kaserman and Mayo (1994).

15 See Kaserman and Mayo (2001).

16 Ibid.

17 For a recent discussion of the rise and fall of the CLEC industry, see Burton, Kaserman and Mayo (2002).

18 Indeed, in support of the $\$ 35$ settlement rate, the Staff of the New York Public Service Commission argued that the $\$ 185$ charge initially ordered by the Commission (and, thus even greater charge sought by the incumbent) would create "a serious barrier to those CLECs trying to migrate their customer bases away from Verizon's switches" and that the lower rate would improve "the likelihood that facilities-based competition will continue to develop." See Prepared Testimony of Charles M. Dickson, et al., In the matter of VerizonNew York, Case 00-C-1945, February 2002.
} 
perpetuation of cross subsidies in retail telecommunications markets. For many years, economic analysis suggested that the rates for residential, rural, primarily local exchange consumers were held artificially low and perhaps below the incremental cost of serving these customers. ${ }^{19}$ More recently, the Supreme Court acknowledged this crosssubsidization when it stated:

In order to hold down charges for telephone service in rural markets with higher marginal cost due to lower population densities and lesser volumes of use, urban and business users were charged subsidizing premiums over the marginal costs of providing their own service. ${ }^{20}$

As the Court notes, the revenues necessary to continue to offer such low (and, arguably, subsidized) rates were derived by charging high rates to businesses and urban customers and to consumers with relatively large amounts of long-distance usage. While the existence of a subsidy to the aggregated set of local exchange services has increasingly been questioned, it certainly remains true that the long-standing practice of keeping rates artificially low for rural, residential local exchange customers remains very much in place in a number of locations around the country. Naturally, there can be no more effective barrier to entry into a market than rates that are held below costs. New entrants simply cannot be expected to enter retail residential markets where the rates for these services are artificially held below their respective economic cost. The result is that regulators are faced with a serious challenge: to allow the rates for subsidized services to rise to at least cover the economic cost of providing the services. ${ }^{21}$ At that point new entrants may find service to these segments of the communications sector profitable to serve.

Setting aside pricing issues, the second critical obstacle in this realm facing new entrants is - somewhat ironically in the face of the Court's proper interpretation of the Act - access to economically efficient rates once they are established. Consider, for example, the following. In many situations, new entrants find that the most efficient type of access for the provision of local exchange service for businesses beyond a minimal size, is nonswitched access. In these circumstances, the provision of non-switched access has been identified as an "element" under the Telecommunications Act. Accordingly, it would seem very natural to make this element available to new entrants at its TELRIC rates. To date, however, the ILECs have denied new entrants access to the economically efficient rate, making such access available only at "special access" rates, which are often well above the TELRIC levels. Indeed, special access rates generally exceed the forward-looking costs that are incurred by the ILEC if it were to provide the same service to a retail customer. This denial of access to economically efficient rates acts as a classic barrier to entry by creating a cost asymmetry between the new entrants the incumbent. ${ }^{22}$ Again, this problem is remediable. To salvage the hopes for the development of a truly competitive local exchange industry, however, regulators will need to move quickly and aggressively to

\footnotetext{
19 See, e.g., Palmer (1992)

20 Opinion, p. 7

${ }^{21}$ Concerns that such price increases will harm the ability to achieve the policy goal of universal telephone service are almost certainly misplaced. See, e.g., Kaserman and Mayo (1997) and Eriksson, Kaserman and Mayo (1998) who show that targeted programs to subsidize those consumers most in need of the subsidy to support subscription is far preferable on both theoretical and practical grounds to the present policy of repressing rates to the entire class of residential consumers.

${ }^{22}$ See Stigler (1968) for a discussion of barriers to entry stemming from cost asymmetries between incumbents and prospective entrants.
} 
ensure that new competitors are not denied economically efficient rates once they are established.

\subsection{Non-price exclusionary practices}

Perhaps the greatest obstacle to effective implementation of a C-E regulatory policy is the inherent inability of regulators to enforce non-discrimination rules on incumbents that hold monopoly power over inputs required by new entrants. ${ }^{23}$ While input prices can be set and reasonably well enforced, it is nearly impossible for regulators to prevent degradation of the quality of these inputs. Particularly in network industries, the cause of a service disruption can be difficult to ascertain. And, once ascertained, the intent of the culpable party can be even more difficult to establish. Moreover, quality degradation can be just as (or, perhaps, more) effective as above-cost input prices in impeding entry into local exchange markets, because such degradation can adversely affect new firms' reputations and thereby inflict long-lasting effects.

A recent series of papers has shown that, under circumstances that closely approximate those exhibited by local exchange markets, such quality degradation or "sabotage" can be a profitable (and, therefore, likely) strategy. ${ }^{24}$ And specific factual evidence of such behavior from the ILECs appears to corroborate the theory. For example, an investigation in New York recently revealed that Verizon has averaged $74 \%$ of its appointment met in the provisioning of Special Access to its downstream competitors while it has averaged $94 \%$ of its appointments met for its own retail operations. The Commission concluded that "the record suggests that Verizon treats other carriers less favorably than its own end users". 25 More general evidence that the ILECs have implemented this strategy is revealed in the substantial fines that regulatory commissions have levied for ILEC violations of the nondiscrimination provisions of the 1996 Act. Nonetheless, despite these fines, we suspect that non-price discrimination will continue. The stakes are simply too high and detection too difficult for such behavior to be effectively discouraged.

Moreover, one of the papers on this subject demonstrates that the incentive for an incumbent monopolist to engage in sabotage increases with the stringency of regulation applied to the prices for the inputs purchases by those entrants. ${ }^{26}$ In effect, the less profit the incumbent is able to extract on the inputs supplied to its rivals, the greater the incentive to exercise its monopoly power in other dimensions. This result, in turn, suggests, somewhat ironically, that the Court's endorsement of TELRIC pricing of UNEs is likely to exacerbate the quality degradation problem. That is, as UNE prices are pushed closer to their long-run incremental costs, the more sabotage we are likely to see.

\subsection{Removal of the regulatory "carrot"}

Recognizing both the need for ILECs to cooperate with entrants in providing essential inputs and the obvious incentive for ILECs to refuse such cooperation, Congress

\footnotetext{
23 See Stelzer (1997).

24 See, for example Economides (1998), Mandy (2000); Beard, Kaserman and Mayo (2002); and Reiffen and Ward (2002).

25 See Opinion and Order Modifying Special Services Guidelines for Verizon New York, Inc., Conforming Tariff, and Requiring Additional Performance Reporting, Case 00-C-2051, Case 92-C-0665, Issued and effective June 15, 2001.

26 See Beard, Kaserman and Mayo (2001).
} 
incorporated the Section 271 provision of the 1996 Act. That provision attempts to provide an incentive for incumbent monopolists to facilitate entry by holding out a reward. Specifically, under this provision, RBOCs are allowed to reintegrate into in-region interLATA long-distance once they have sufficiently opened their local exchange markets to competition. The legislative standards that must be satisfied to meet this condition involve both an explicit checklist of entry-facilitating actions (e.g., installation of nondiscriminatory operational support systems needed for processing new service orders for new entrants and maintaining billing and service functions once established) and a much less explicit requirement that the approval of reintegration be "in the public interest". Predictably, the regulatory proceedings to implement these provisions have been prolonged and contentious as the RBOCs have sought approval to re-enter the long-distance market and these petition have generally been seen as premature by the incumbent interexchange carriers. $^{27}$

To date, the FCC has approved RBOC reintegration in 15 states. Whether such reintegration will benefit consumers is an empirical question for which there is, as yet, insufficient data to meaningfully address. Nonetheless, regardless of the merits of the individual reintegration orders, it is clear that once RBOC reintegration is approved, the Section 271 incentive to cooperate with entrants disappears. Like the proverbial carrot, that incentive can exist only until the object that is providing the incentive is consumed. Thus, while the Court's Opinion may tend to facilitate CLEC entry, ceteris paribus, in fact, all else is not equal. To the extent that the FCC approves more Section 271 applications for reintegration, the incentives for ILEC cooperation will evaporate. Moreover, there is compelling evidence that these incentives are likely to affect firm behavior. Indeed, in a recent study of the post-Act behavior of RBOCs (which had not secured reintegration) and GTE (which was integrated into long-distance), Mini (2001) found that in the absence of the "carrot" for cooperation firms are markedly more likely to adopt aggressive tactics toward new entrants. This will, of course, pose additional challenges to prospective entrants and nascent competitors.

\subsection{Litigation and regulatory uncertainties}

While the Court's Opinion would nominally seem to put an end to costly, time-consuming and entry-retarding legal and regulatory wrangling over pricing and unbundling issues, a realistic assessment suggests that rather than putting an end to such debate it will only change the venue for continued legal and regulatory manoeuvring by the ILECs. Indeed, in the wake of the Court's opinion Verizon immediately announced that it would continue to fight the pricing and unbundling rules at the FCC.

As a Verizon spokesman stated: "Just because something is legal does not mean it is good public policy. ${ }^{28}$ In light of statements such as this and the ongoing incentive by the ILECs to preserve their monopoly power, it is very likely that state and federal regulators and in all likelihood, the courts - will continue to see efforts on the part of the ILECs to deter entry. For instance, in the immediate wake of the announced intention by AT\&T to enter local exchange markets in Ohio, SBC has recently proposed to sharply increase UNE

\footnotetext{
${ }^{27}$ Under the Act, these proceedings take place before state regulatory commissions. The ultimate decision to approve RBOC reintegration, however, lies with the FCC.

28 Stern (2002). See also the letter of William Barr, Executive Vice President and General Counsel, Verizon to Michael Powell, Chairman of the Federal Communications Commission, July 16, 2002.
} 
rates. SBC's proposal is to increase existing loop rates of less than $\$ 6$ to over $\$ 17.50$ per loop per month. Similarly, SBC proposes to increase local switching charges by rates up to 6000 percent. ${ }^{29}$ The willingness and ability by ILECs to fund such legal and regulatory maneuvers, even if they ultimately prove unsuccessful, are likely to serve to blunt whatever economic incentives the market may be otherwise sending to prospective entrants on the merits of entry.

Finally, the recent opinion fails to resolve an issue that will, most certainly, continue to preoccupy policymakers in the implementation of TELRIC prices. Specifically, low UNE prices and relatively favorable wholesale rates can obviously facilitate entry into the retail stage of local exchange telecommunications markets. They cannot, however, break the monopoly that the ILEC's continue to hold over the upstream network infrastructure that ultimately must be accessed to provide service to final customers. And, until that monopoly is broken, difficult regulatory problems will persist and complete deregulation will remain a distant dream.

Two separate arguments have appeared concerning the UNE pricing policy that is more likely to foster the upstream facilities-based entry needed to break the last-mile monopoly. First, the ILEC's and their supporters have argued that relatively high UNE prices are more likely to promote the necessary network-stage entry. Low resale and lease prices, they argue, will cause investment in facilities to be unattractive, as entrants can purchase these inputs from incumbents more cheaply than they can build them. In addition, resale (unintegrated) entry carries substantially less risk, as sunk costs are largely avoided. As a result, while low UNE and wholesale prices may create the illusion of competition by enticing firms to enter the retail stage of the industry, they will, in fact, discourage the sort of entry that is ultimately required if effective competition is ever to materialize. This view, then, sees resale and facilities-leased entry as substitutes - we can encourage one only at the expense of the other.

Potential (and actual) entrants have countered this argument, pointing out that resale entry can help to pave the way for subsequent facility investments. Under this logic, de novo, vertically integrated entry into local exchange markets through replication of the ILEC's network facilities is unlikely due to the substantial sunk costs associated with such entry. Those sunk cost, however, can be at least partially nullified by prior successful resale entry. Specifically, non-integrated entry at the retail stage can provide entrants an established customer base which reduces the likelihood that these firms subsequently will be forced to exit. This reduced profitability of exit, in turn, lowers the risk associated with upstream, sunk-cost facilities investments. Thus, these parties view resale entry as a vehicle for promoting facilities-based entry. That is, the two forms of entry are seen as complements, not substitutes. To support this view, they point to experience in the longdistance market, where substantial resale entry preceded much of the facilities-based entry that subsequently occurred.

Which of these two competing arguments is correct? Unfortunately, that question cannot be answered definitively on a priori theoretical grounds alone. Our own view is that, as long as UNE (and other input) prices are not pushed below the forward-looking, long-run incremental costs of constructing and maintaining the underlying network

\footnotetext{
29 SBC Ameritech Ohio's Application for Approval of Unbundled Network Element Prices, In the Matter of the Review of Ameritech Ohio's TELRIC Costs for Unbundled Network Elements Case No. 02-1280-TPUNC, Filed May 31, 2002.
} 
facilities (i.e., as long as these prices are not subsidized), the latter argument is more convincing. Once retail-stage entrants have established sufficient customer bases, incentives to integrate backward to self-supply essential network facilities will encourage these firms to undertake the additional investments needed to break the final source of monopoly power in this industry.

At the same time, even in the presence of resale entry, the wherewithal to break that monopoly may have to await some further technological advancement. If that is the case, then, regardless of the level at which UNE prices are set, we are unlikely to observe sufficient entry at the network level to bring about effective competition at all stages until technological change enables that which regulatory rules cannot.

\section{Conclusion}

Most economists would agree that incumbent monopolists are unlikely to voluntarily cede their monopoly power. In the telecommunications industry, the mere fact that a law was passed which embraced competition should not realistically have been expected to be met by the incumbent monopolists with a warm embrace of new entrants. Indeed, as should have been expected, ILECs have deployed a number of tactics (economic, regulatory and legal) to retain their control of the principal source of their monopoly power; namely, access to the local loop or the so-called last mile monopoly. These tactics have resulted in arguments, inter alia, that regulators have overstepped their jurisdiction in their zeal to foster competition; that the prices chosen by regulators are confiscatory and, therefore, illegal; and that even if the regulators have the authority to establish these rates, the applicability of the prices set should be imposed only under the most narrow interpretation of the Act.

In this paper, we have argued that the most fundamental lesson to be drawn from the Supreme Court's ruling is that Congress did not intend to continue to allow monopolists to remain entrenched in local exchange telephone markets. Rather, Congress intended that regulators would pursue fundamentally different and more activist policies designed to enable competition in local exchange markets. While a narrow interpretation of the most recent Supreme Court Opinion - that TELRIC pricing is legal and that regulators can require ILECs to sell UNEs as a bundled set - is welcome, the Opinion's more basic message is that regulators should perceive a green light, indeed a mandate, to implement more active policies designed to open local exchange markets to competition. In this regard, we have identified a number of critical issues that continue to confront new entrants in the wake of the Opinion and which will require that affirmative and decisive competition-enabling policies be adopted if local exchange competition is to take root anytime soon. Moreover, this must be accomplished in an environment in which the incumbents will, most certainly, continue to use whatever means are available to them to slow the erosion of their monopoly power. 


\section{$5 \quad$ References}

Beard, T. Randolph, David L. Kaserman and John W. Mayo. (2001) "Regulation, Vertical Integration and Sabotage," Journal of Industrial Economics, 49: 319-334.

Beard, T. Randolph, David L. Kaserman and John W. Mayo. (2002) "On the Impotence of Imputation," mimeo.

Burton, Mark L., David L. Kaserman and John W. Mayo. (2002) "Shakeout or Shakedown? The Rise and Fall of the CLEC Industry" in Markets, Pricing, and Deregulation of Public Utilities, Michael Crew, Editor, Kluwer Academic Press, Boston, MA.

Economides, Nicholas. (1998) "The Incentive for Non-Price Discrimination by an Input Monopolist," International Journal of Industrial Organization, 16: 271-284.

Eriksson, Ross C., David L. Kaserman and John W. Mayo. (1998) "Targeted and Untargeted Subsidy Schemes: Evidence from Postdivestiture efforts to Promote Universal Telephone Service," Journal of Law and Economics, 41: 477-502.

Kahn, Alfred E. (1984) “The Road to More Intelligent Telephone Pricing," Yale Journal on Regulation, 1: 139-158.

Kaserman, David L. and John W. Mayo. (1984) "Cross Subsidies in Telecommunications: Roadblocks on the Road to More Intelligent Telephone Pricing," Yale Journal on Regulation, 11: 119-147.

Kaserman, David L. and John W. Mayo. (1997) “The Quest for Universal Service: The Missfortunes of a Mishappen Policy," in Telecommunications Policy: Have Regulators Dialed the Wrong Number?, DL. Alexander, editor, Praeger Publishing Group, Westport, CT.

Kaserman, David L. and John W. Mayo. (1999) "Regulatory Policies toward Local Exchange Companies under Emerging Competition: Guardrails or Speedbumps on the Information Highway?" Information Economics and Policy, 11: 367-388.

Kaserman, David L. and John W. Mayo. (2001) "Efficient Telecommunications Policies for the 'New Economy,': The Compelling Case for Access Charge reform," International Journal of Development Planning Literature, Vol 1, Nos. 1 \& 2, January \& April: 61-78.

Mandy, David M. (2000) "Killing the Goose that May have Laid the Golden Egg: Only the Data know whether Sabotage Pays," Journal of Regulatory Economics, 17: 157-172.

Mini, Federico. (2001) "The Role of Incentives for Opening Monopoly Markets: Comparing GTE and BOC Cooperation with Local Entrants," Journal of Industrial Economics, 49: 379-414. 
Palmer, Karen. (1992) “A Test for Cross Subsidies in Local Telephone Rates: Do Business Customers Subsidize Residential Customers?" RAND Journal of Economics, 23: 415-431.

Reiffen, David and Michael R. Ward. (2002) Recent Empirical Evidence on Discrimination by Regulated Firms," Review of Network Economics, 1: 39-53.

Stelzer, Irwin M. (1997) “Vertically Integrated Utilities: The Regulators' Poison'd Chalice," The Electricity Journal, 10: 20-29.

Stern, Christopher. (2002) "High Court Backs FCC On Phone Networks: Local Firms' Rivals Win Fight for Access," Washington Post, May 14: E1.

Stigler, George. (1968) “The Organization of Industry”, Homewood, Ill, Irwin. 